Ind. Health, 1964, 2, 55.

\title{
DETERMINATION OF DUST CONCENTRATION IN THE AIR BY SCATTERED LIGHT
}

\author{
Shigezi KOSHI \\ National Institute of Industrial Health, Kizuki-Sumiyoshi, Kawasaki \\ (Received September 23, 1963)
}

\begin{abstract}
The circuit, in which the photoelectric current of photomultiplier was transformed to digital amount, was developed. This A-D transformation circuit is very simple and has a high sensitivity. The photoelectric current of $5 \times 10^{-4} \mu \mathrm{A}$ is transformed into one pulse per minute by this circuit. Three kinds of apparatus for the determination of aerosol concentration were devised by means of measuring the intensity of scattered light by this circuit.

Responses of these devices are linearly proportional to dust concentration in the same aerosol systems.

These apparatus can measure the concentration of the order of $10^{-3} \mathrm{mg} / \mathrm{m}^{3}$ of quartz dust. Significance of dust determination by these devices was also disscussed.
\end{abstract}

\section{INTRODUCTION}

For the estimation of relative dust concentration in the air, many methods by the measurment of the intensity of scattered light by dust particles have been tried.

Leitz Tyndallometer and Tyndalloscope are well known among various such devices.

The author ${ }^{1)}$ also designed Dustallo to determine the intensity of scattered light by particles using photomultiplier instead of the colorimetry applied to Tyndallometer and Tyndalloscope.

The recording device of the scattered light intensety by photomultiplier and D.C. amplifier is also practically used.

There is also counting apparatus of particle number developed by F. T. Gucker and C. T. Okonski ${ }^{2}$ ) using the principle of light scattering.

Values of relative dust concentration by Tyndalloscope, Dustallo and the photoelectric recording device correlate the dimension of the amount of particles per unit air volume. On the other hand, the value obtained by the photoelectric pulse counter of Gucker and Okonski has the dimension of the number of particles and the measured value must be divided by sampling air volume for the determination of dust concentration.

Of course, the measurment of sampling air volume is also needed in the determination of air borne dust concentration by Thermal precipitater, Cascade impactor, Impinger and Filter paper dustometer ${ }^{3)}$ etc. 


\section{S. KOSHI}

The accurate measurment of air volume passing through the sampling device is very difficult because of the pressure drop of apparatus itself and the change of flow resistance of sampling part. Incorrectness of the measurment of sampling air volume affects the estimated value of dust concentration.

The method evaluating the dust by the dimension of concentration does not need the determination of sampling air volume for the estimation of dust concentration.

Tyndalloscope and Dustallo are very convenient for the estimation of relative dust concentration in the air, as they are portable, but the relative sensitivity of these devices is not sufficient for the evaluation of dust concentration below $1 \mathrm{mg} / \mathrm{m}^{3}$. The device for the measurment of light intensity could be more sensitive, by the use of photomultiplier and D. C. amplifier, but the size of the device should be large, and the field of application be limited.

The author devised a method of measurment of very weak light intensity by the A-D (analogue to digital) transformation of photoelectric current of photomultiplier.

Three kinds of apparatus for measurment of dust concentration were ciesigned by this principle.

\section{BASIC CiRCUIT}

The A-D transformation circuit and the relay circuit are shown in Figs. 1 and 2.

Photoelectric current is transformed into digital amount in this circuit by the following procedure.

The condenser C in Fig. 1 is discharged by photoelectric current of photomultiplier MS-9S. When the electric potential of condenser $\mathrm{C}$ reaches to a fixed value, the condenser $\mathrm{C}$ is charged through the neon tube N. L. . At this moment, potential difference is produced at both ends of the resistor $\mathrm{R}$. Then the electric pulse is obtained

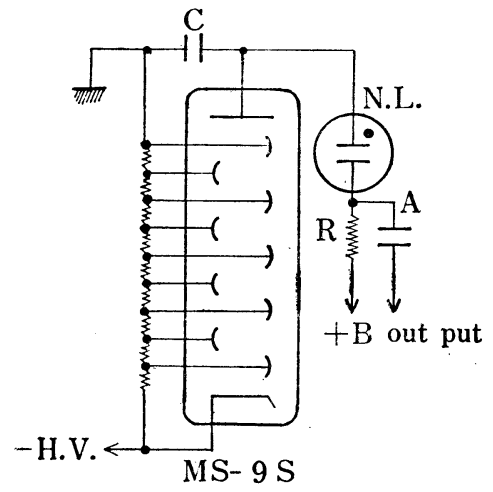

Fig. 1. A-D transformation circuit.

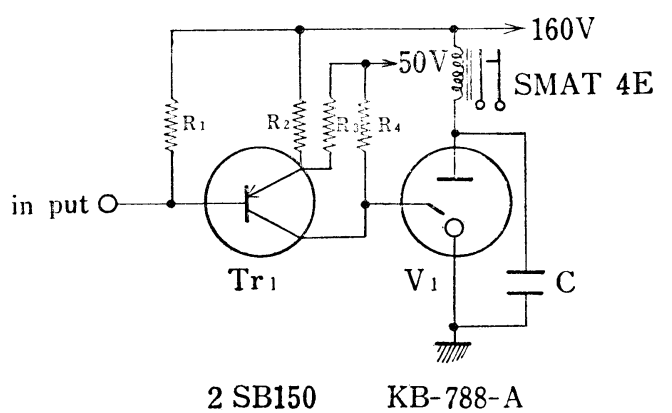

Fig. 2. The relay circuit.

$\begin{array}{ll}R: 2 \mathrm{OK} & C: 1 \mu \mathrm{M} . \mathrm{P} .250 \mathrm{WV} \\ R: 5 \mathrm{~K} & T r: 2 \mathrm{SB} 150 \\ R: 25 \mathrm{OK} & V: \text { KB-788-A } \\ R: 100 \mathrm{~K} & \end{array}$




\section{DETERMINATION OF DUST CONCENTRATION}

at the point $\mathrm{A}$ in Fig. 1. This pulse has a height equal to the difference between starting potential and preservation potential of neon tube, and a width depends on the capacity of condenser $\mathrm{C}$ and the resistor $\mathrm{R}$.

Shapes of pulses observed at the point A corresponding to various capacities of condenser are shown in Figs. 3 a-3 e.

The character of this A-D transformation circuit corresponding to various capacities of condenser are shown in Table 1. Column A shows the pulse width and column $B$ pulse interval when a definite light beam is emitted to the photomultiplier. The possible maximum number of pulses per minute with the error below $1 \%$ is shown in column C.

Where N. L. is NL-68, R is $50 \mathrm{~K} 2$, the electric potential of point $+B$ is $108 \mathrm{~V}$ and the potential of cathode of photomutiplier MS-9S is $-460 \mathrm{~V}$.
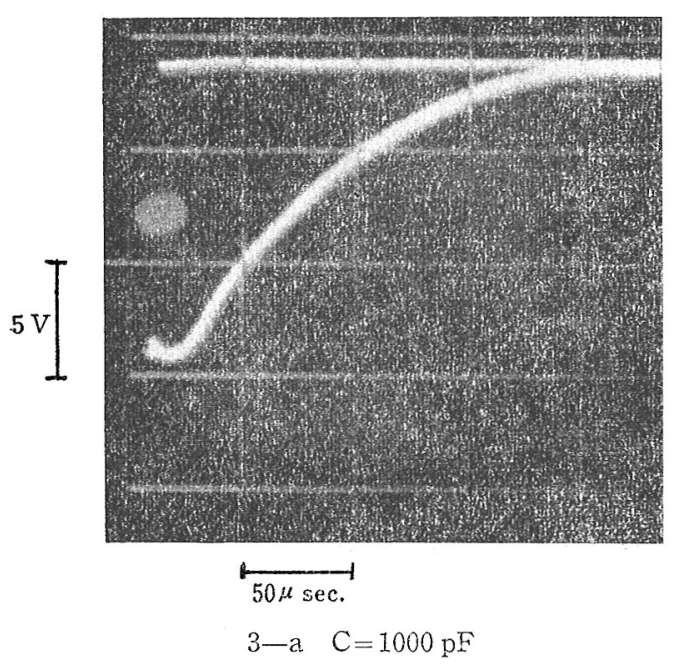

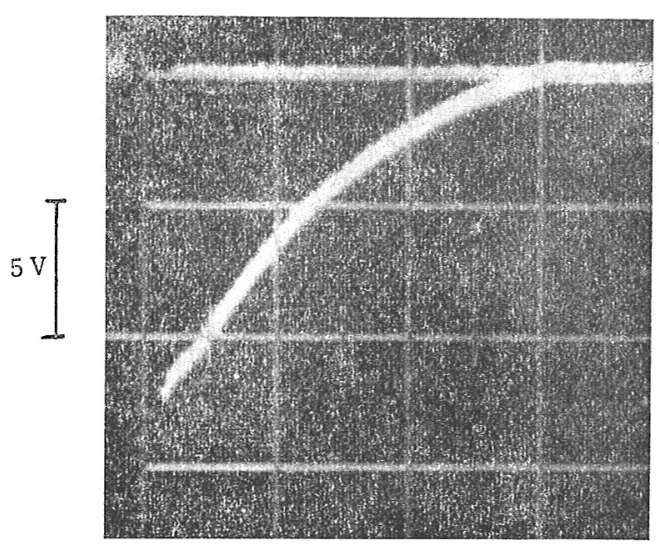

$$
\vdash_{100 \mu \text { sec. }}
$$$$
\text { 3-b } \quad \mathrm{C}=2000 \mathrm{pF}
$$

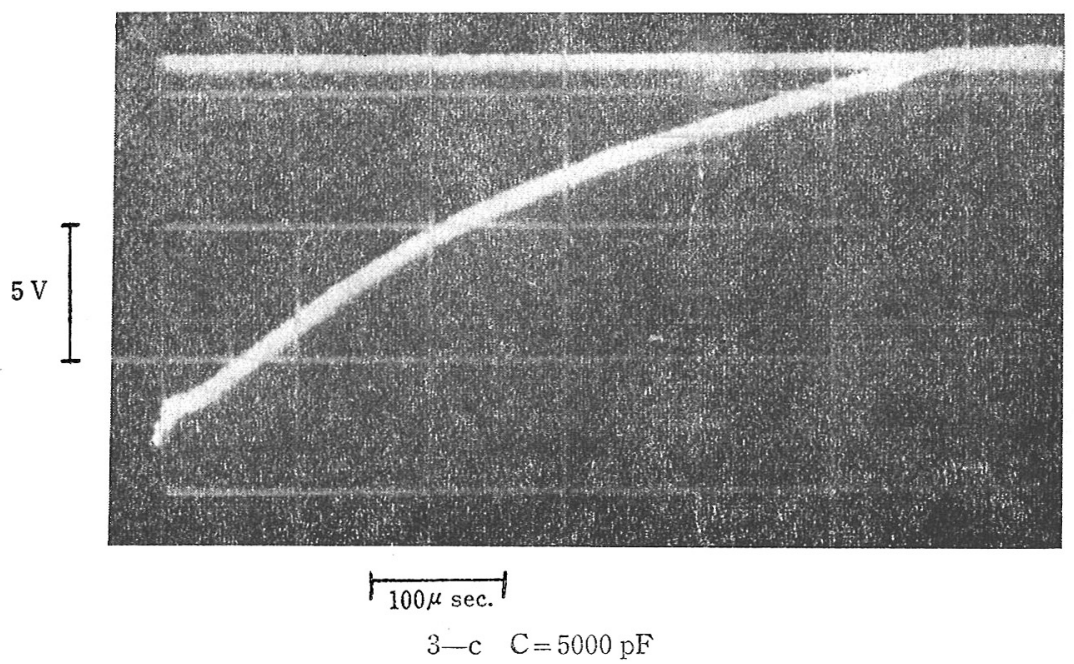



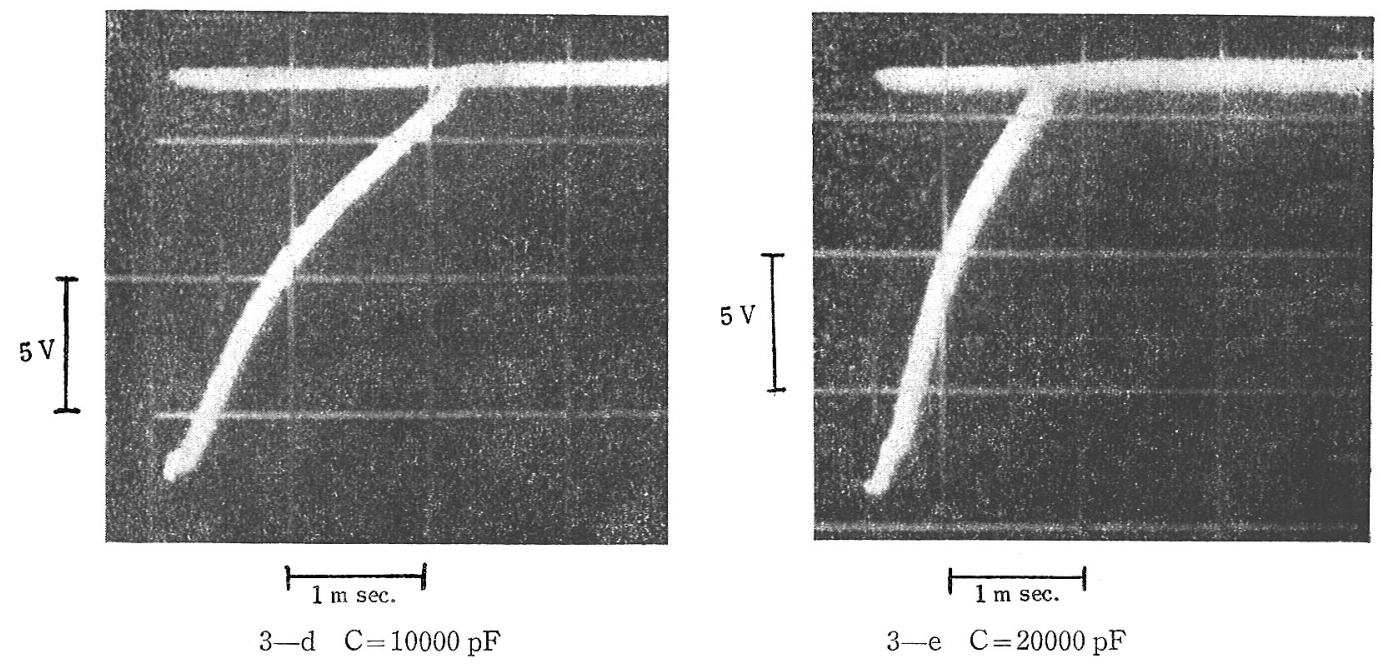

Fig. 3. The shape of pulse generated from A-D transformation circuit.

Table 1. The character of A-D transformation circuit for various capacities of condenser.

\begin{tabular}{c|ccc}
\hline Capacity of condenser & Width $\stackrel{(\text { A) }}{\text { of }}$ pulse & Pulse interval & Max. count rate \\
\hline $1000 \mathrm{pF}$ & $180 \mu \mathrm{sec}$ & $37 \mathrm{msec}$ & 3333 c.p.m. \\
2000 & 290 & 72 & 2070 \\
5000 & 570 & 160 & 1051 \\
10000 & 1200 & 287 & 500 \\
20000 & 2000 & 591 & 286 \\
\hline
\end{tabular}

In this transformation circuit, the photoelectric current corresponding to one pulse can be calculated from the photoelectric current and the numcer of pulses generated for unit time. From the results of observation, it was found that the generation rate of pulses for photoelectric current of $0.8 \mu \mathrm{A}$ was $1620 \mathrm{c.p} . \mathrm{m}$. (count per minute), where $\mathrm{C}$ was $1000 \mathrm{pF}$. Then, one pulse per minute corresponds to about $5 \times 10^{-4} \mu \mathrm{A}$ of photoelectric current. This value of photoelectric current corresponds to the pencil of light of $5 \times 10^{-12} \mathrm{~m}$., if the plate sensitivity of photomultiplier is $100 \mu \mathrm{A} / \mu \operatorname{lm}$.

The dark current from photomultiplier and other electric parts can not be neglected as the response of transformation circuit is very sensitive. In order to reduce the dark current from tranformation circuit, the socket of photomultiplier is closed tightly in the vessel with desiccant, after the condenser $\mathrm{C}$, roading resistors of photomultiplier and the neon tube were soldered directly to the pins of photomultiplier.

The neon tube is specially treated to reduce the electric leakage. Consequently, the impedance of transformation circuit was increased to about $10^{12} \Omega$, and the disturbance by the pulse generated from dark current was minimized. 


\section{DETERMINATION OF DUST CONCENTRATION}

In the relay circuit shown in Fig. 2, the relay discharge tube $V_{1}$ is discharged by the input pulse inversed through the $\operatorname{Tr}_{1}$. The each input pulse is registered to mechanical register connected to contact point of relay SMAT-4E.

The light intensity is indicated by the registered number for a fixed time.

This method of measurment of scattered light intensity was applied to design of the dust indicator.

\section{Application of Basic Circuit}

\section{a) Dust Indicator for the Use in Wide Field}

The measuring apparatus of relative dust concentration was devised for the use in wide field. This device is very useful for the following purposes; the measurment of dust concentration in the air over wide range, the estimation of filtering efficiency of dust respirator and air filter, the check of efficiency of dust collector and the test of collecting efficiency of dust sampling apparatus.

The detector used in this apparatus is shown in Fig. 4. S is light source (6V, $40 \mathrm{~W}$ ), $T$ is light trap to avoid the effect of reflected light from inside wall of detector.

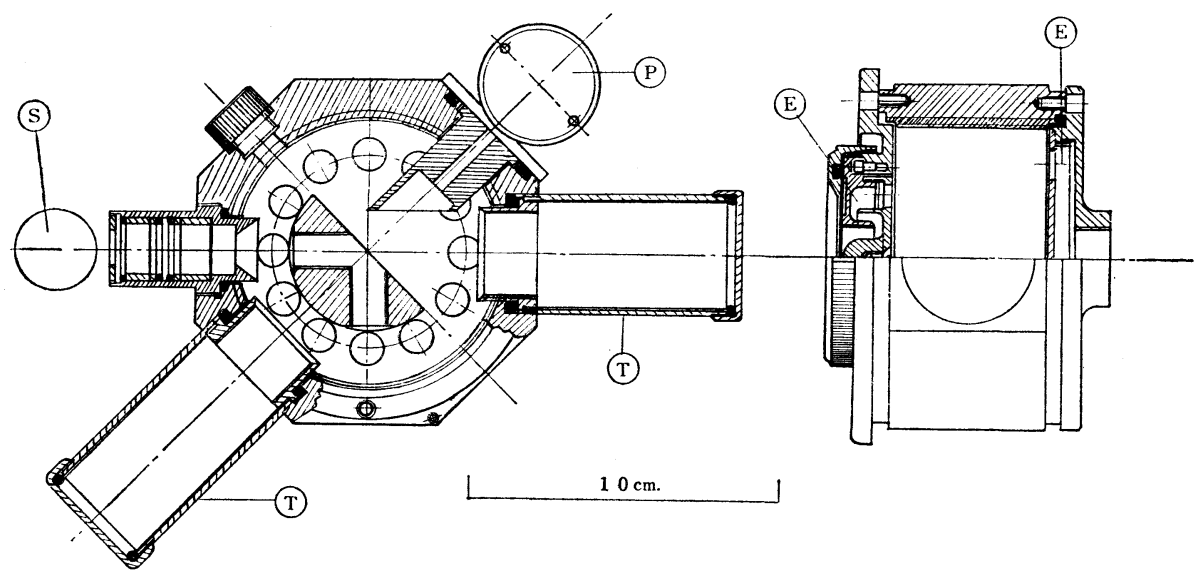

Fig. 4. The section of detecter.

$$
\begin{array}{ll}
\text { S : Light source 6V 40W } & \text { P : Photomultiplier MS-9S } \\
\text { E : Maze } & \text { T: LIght trap }
\end{array}
$$

The air is drawn passing through the detector vertically to the plane of the figure. The scattered light by dust particles at the angle of $135^{\circ}$ for incident beam is received to photomultiplier $\mathrm{P}$ through the hole of $3 \mathrm{~mm}$ in diameter and $30 \mathrm{~mm}$ in length.

This apparatus makes possible the observation of the dust concentration even in cource of aspirating the sample air, as the sample air is drawn through optical mazes arranged at the air inlet and outlet sides of detector.

This apparatus explained in this section is composed of two detectors and two sets of electric circuit as shown in Figs. 1 and 2. 


\section{S. KOSHI}

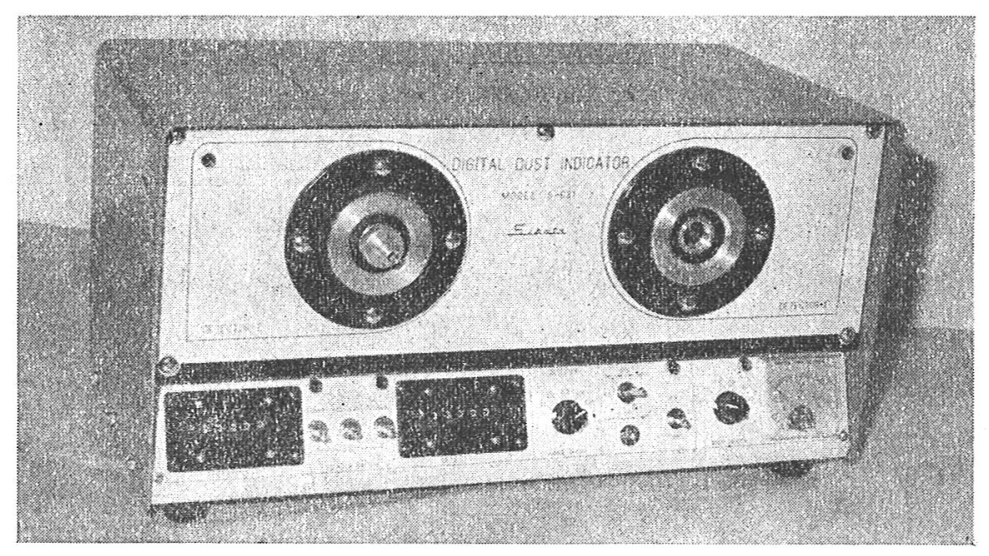

Fig. 5. The dust indicator for the use in wide field.

These two sets of parts can detect dust concentration independently of each other using same light source. This apparatus is shown in Fig. 5.

The relative sensitivity of this apparatus (the ratio of pulse number per minute to dust concentration in sample air) is variable by means of the change of condenser $\mathrm{C}$ in Fig. 1 or adjustment of the negative potential of cathode of photomultiplier by the stabilizer in Fig. 6.

In consideration of the application of this apparatus to various uses, the relative sensitivity of one of the detector is adjusted to 20 times to the other. The response of 1 c.p.m. of the higher sensible detector is adjusted to correspond to the concentration of $0.001 \mathrm{mg} / \mathrm{m}^{3}$ of quartz dust. When the capacity of condenser $\mathrm{C}$ and negative

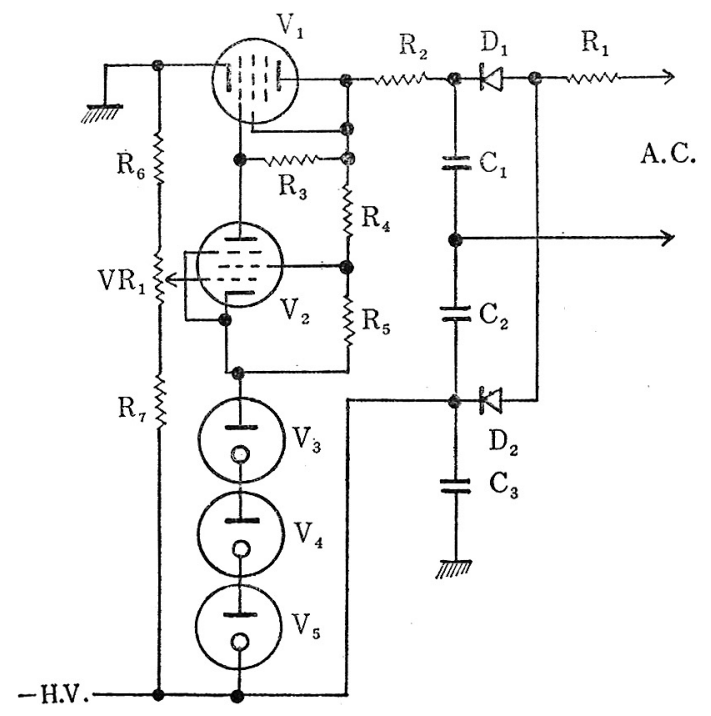

$\mathrm{R}_{1}: 1 \mathrm{~K}$

$\mathrm{R}_{2}: 5 \mathrm{~K}$

$\mathrm{R}_{3}: 500 \mathrm{~K}$

$\mathrm{R}_{4}, \mathrm{R}_{5}: 60 \mathrm{~K}$

$\mathrm{R}_{6}: 1 \mathrm{M}$

$\mathrm{R}_{7}: 2 \mathrm{M}$

$\mathrm{VR}_{1}: 1 \mathrm{M}$

$\mathrm{C}_{1} \mathrm{C}_{2}: 20 \mu \quad 500 \mathrm{WV}$

$\mathrm{C}_{3}: 10 \mu \quad 500 \mathrm{WV} \times 2$

$\mathrm{D}_{1} \mathrm{D}_{2}: 1 \mathrm{~S} 99$

$\mathrm{V}_{1}:$ 6AR5

$\mathrm{V}_{2}:$ : 6AU6

$\begin{array}{lllll}\mathrm{V}_{3} & \mathrm{~V}_{4} & \mathrm{~V}_{5}: \text { VR-150MT }\end{array}$

Fig. 6. The high voltage stabilizer circuit for photomultiplier. 


\section{DETERMINATION OF DUST CONCENTRATION}

high voltage are fixed, the measurable maximum concentration of this apparatus is $20 \mathrm{mg} / \mathrm{m}^{3}$, as the maximum counting rate of register is about 100 c.p.m.

The counting rate from dark current is $3 \pm 1$ c.p.m. in the higher sensible detector and this value is very stable for long period.

\section{b) Portable Dust Indicator}

The principle described in section 2 is especially convenient for the design of portable dust indicator, because the basic circuit is simple and the electric power needed for the operation of the circuit is small.

The cross-section of the detector designed for portable dust indicator is shown in Fig. 7. B is micro fan for the suction of sample air.

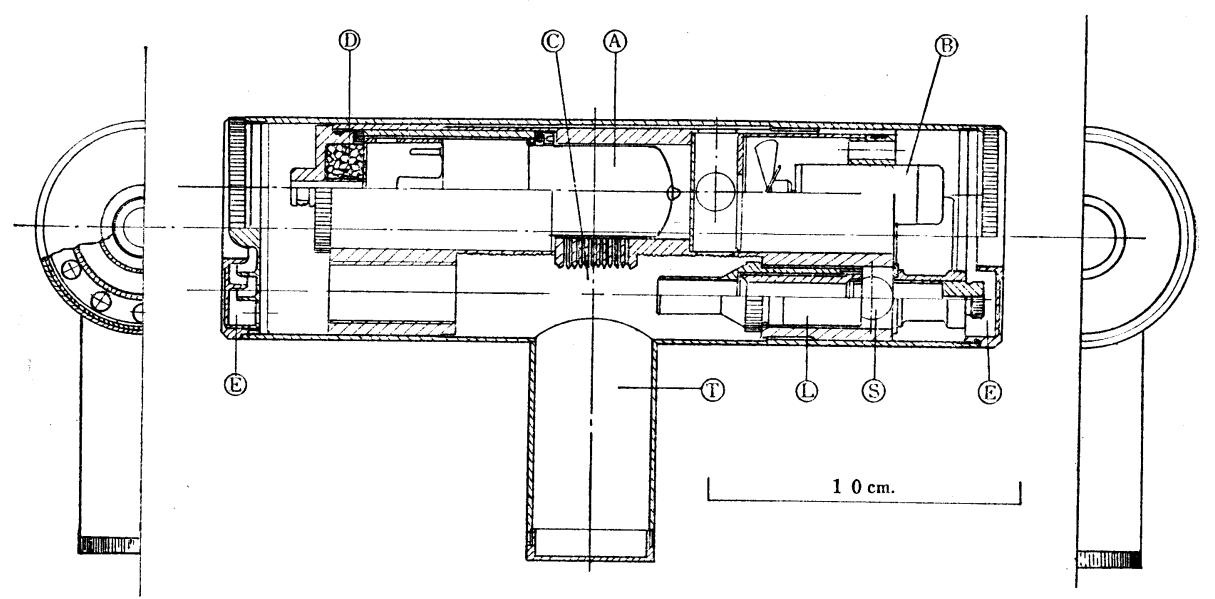

Fig. 7. The section of detecter for portable dust indicater.
$A$ : Photomultiplier MS-9S
$E$ : Maze
$B$ : Micro fan
$S$ : Light source $400 \mathrm{~mW}$
$C$ : Dark chamber
$L:$ Lens system
$D$ : Desiccant
$T$ : Light trap

The sample air from inlet located in left side is drawn passing through optical maze $\mathrm{E}$ and chamber $\mathrm{C}$ by micro fan, and ejectẹd to out side through maze and outlet located in right side. $\mathrm{S}$ is light source of $0.4 \mathrm{~W}$.

The light beam passing through lens system $\mathrm{L}$ is parallel to photomultiplier $\mathrm{A}$.

The scattered light by dust particles in the chamber $\mathrm{C}$ is received to photomultiplier at angle of $90^{\circ}$ to light beam.

Fig. 8 shows the electric circuit of portable dust indicator.

$\mathrm{M}$ and $\mathrm{Cds}$ are ammeter and photocell respectively for the adjustment of light. intensity of source. In order to obtain the electric powers of about $170 \mathrm{~V}$ and $-900 \mathrm{~V}$ for the circuit operation, this circuit has the oscillator composed of the transformer $\mathrm{T}$ and the transister $\operatorname{Tr}_{2}$.

The negative high voltage from the oscillating transformer circuit is maintained to constant by the corona discharge tube $V_{2}$. The A-D transformation circuit and 


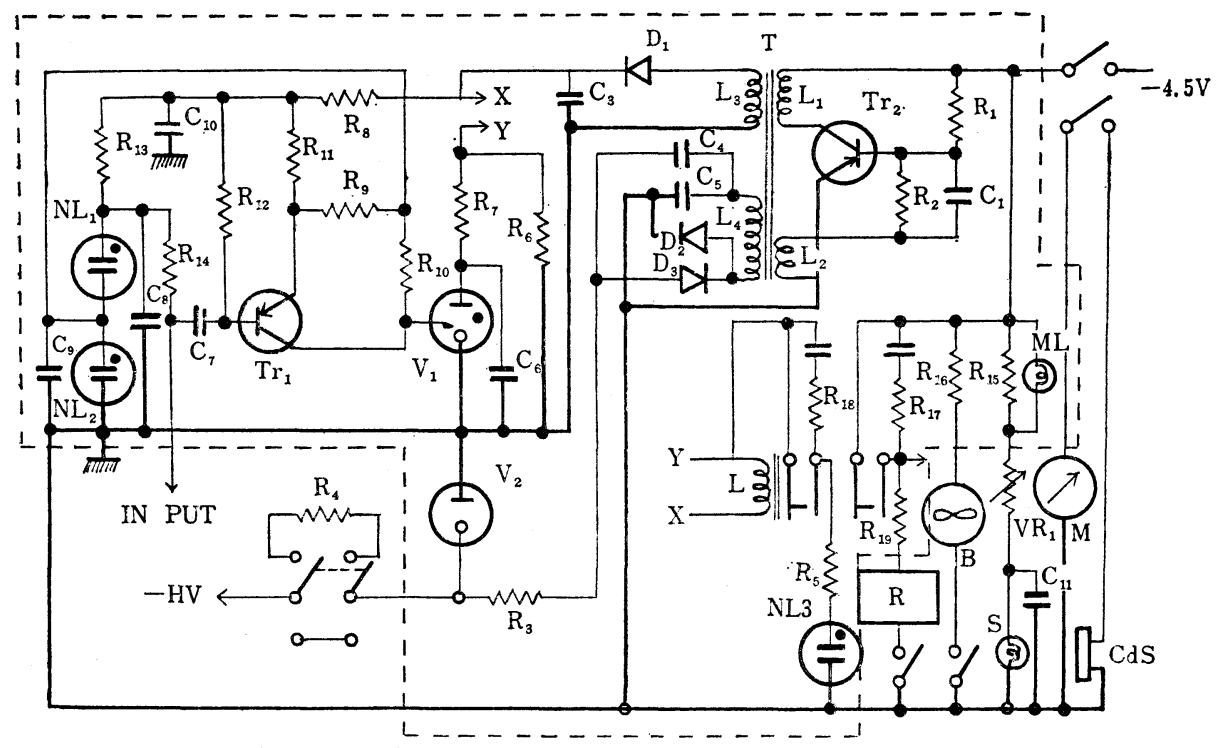

Fig. 8. The circuit of portable dust register.

$\begin{array}{lll}R_{1}: 3 \mathrm{~K} & C_{1}: 0.5 \mu \mathrm{M} . \mathrm{P} .100 \mathrm{WV} & N_{1}, \mathrm{NL}_{2}, \mathrm{NL}_{3}: \mathrm{NL}-68 \\ R_{2}: 2 \mathrm{~K} & C_{2}: 0.1 \mu & T: \text { Ferrite core H EI-40 } \\ R_{3}: 1 \mathrm{M} & C_{3}: 20 \mu 300 \mathrm{WV} & L_{1}: 12 \mathrm{~T} 0.2 \phi \\ R_{4}: 2-5 \mathrm{M} & C_{4}, C_{5}: 2 \mu 500 \mathrm{WV} & L_{2}: 4 \mathrm{~T} 0.2 \phi \\ R_{5}: 500 \mathrm{~K} & C_{6}: 1 \mu \mathrm{M} . \mathrm{P} .250 \mathrm{WV} & L_{3}: 1200 \mathrm{~T} 0.1 \phi \\ R_{6}: 1 \mathrm{M} & C_{7}: 0.002 \mu & L_{4}: 2000 \mathrm{~T} 0.05 \phi \\ R_{7}: 10 \mathrm{~K} & C_{8}: 1 \mu 150 \mathrm{WV} & M: \text { ammeter } 100 \mu \mathrm{A} \\ R_{8}: 50 \mathrm{~K} & C_{9}: 1 \mu 150 \mathrm{WV} & C d S: \text { Cd S cell } \\ R_{9}: 250 \mathrm{~K} & C_{10}: 3 \mu 150 \mathrm{WV} & M L: \text { micro lamp } 60 \mathrm{~mW} \\ R_{10}: 100 \mathrm{~K} & C_{11}: 2000 \mu 6 \mathrm{WV} & S: \text { lamp } 400 \mathrm{~mW} \\ R_{11}: 5 \mathrm{~K} & V R_{1}: 30.5 \mathrm{~W} & B: \text { micro fan } \\ R_{12}: 20 \mathrm{~K} & D_{1}: 1 \mathrm{~S} 183 & R: \text { register } \\ R_{13}, R_{14}: 50 \mathrm{~K} & D_{2}, D_{3}: 1 \mathrm{~S} 99 & L: \text { relay F. Bv. } 151 \mathrm{e} 01 / 1 \\ R_{15}: 101 \mathrm{~W} & T r_{1}: 2 \mathrm{SB} 150 & \\ R_{16}: 30 & T_{1}: 2 \mathrm{SB} 201 & \\ R_{17}, R_{18}: 50 & V_{1}: \mathrm{KB}-788-\mathrm{A} & \\ R_{19}: 21 \mathrm{~W} & V_{2}: \mathrm{VR}-700-\mathrm{SM} & \end{array}$

relay circuit are the same as in Figs. 1 and 2. The input of relay circuit is connected to the point $A$ in Fig. 1. The print circuit (as shown in Fig. 9) is used for the inner circuit rounded by dotted line in Fig. 8. The weight of this print circuit is about $200 \mathrm{~g}$. The electric power for the operation of this circuit is only $1.4-1.8$ watt. Then the apparatus is operated satisfactorily by 6 dry cells of $1.5 \mathrm{~V}$ or 2 midget batteries of $2 \mathrm{~V}$.

The measurable range of dust concentration by this apparatus covers from 0.1 $\mathrm{mg} / \mathrm{m}^{3}$ to $200 \mathrm{mg} / \mathrm{m}^{3}$ for quartz particle. The counting rate by dark current is a few count per minute. 


\section{DETERMINATION OF DUST CONCENTRATION}

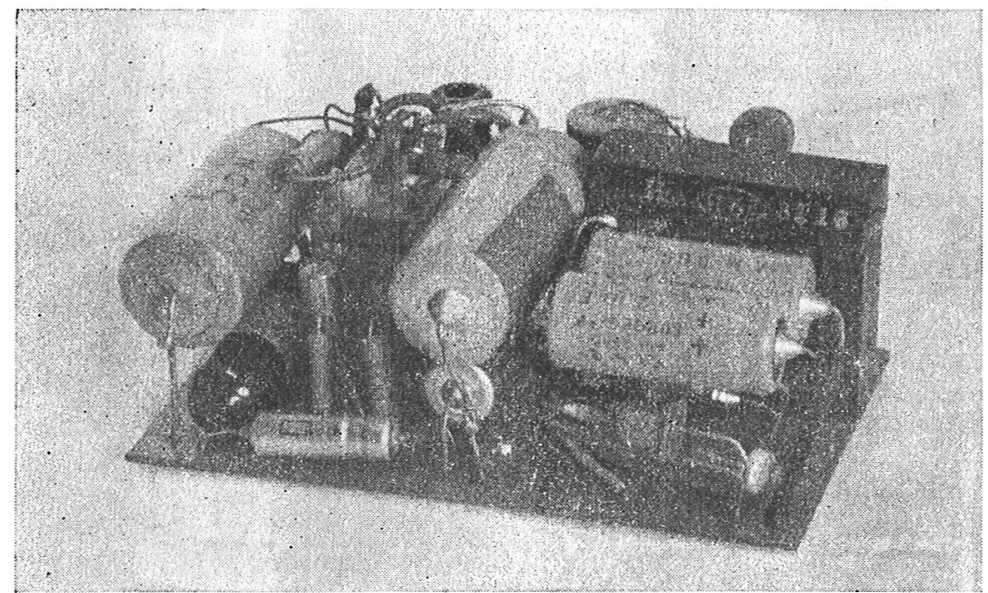

Fig. 9. Print circuit of portable dust indicator.

\section{c) Automatic Register for the Concentration of Atmospheric Particulate Matter}

In the method of measurment of dust concentration discussed in this paper, the response has a dimension of concentration (amount of particle per unit air volume) and the photoelectric current by scattered light is transformed into digital amount.

These principal natures of this method are convenient for the design of an automatic register of the concentration of atmospheric particulate matter.

Fig. 10 shows the flow sheet of apparatus. The detector, transformation circuit and relay circuit used in this apparatus are the same as those discussed in section $3 \mathrm{a}$ ).

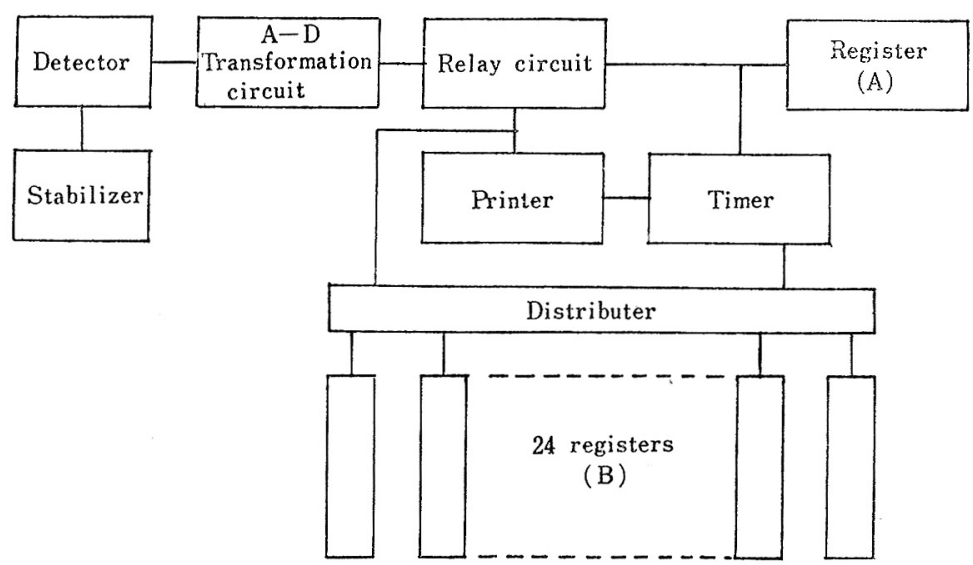

Fig. 10. The flow sheet of automatic register for atmospheric particulate matter.

Output pulses from contact point of relay are registered to each register at the same time by the following procedure.

Pulses are registered 1) to registor (A) for the measurment of total number of pulse accumulated for one month;2) to one of the 24 registers (B) through the distributer in which the pulse generated in any one hour is distributed to the register 


\section{S. KOSHI}

corresponding to that hour; and 3) to printing register in which the number of pulse in each one hour is printed automatically. Thus, by this apparatus, the average concentration of aerial particulate matter for one month, the average diurnal variation for month at the interval of one hour and the average concentration for each one hour are obtained.

A sample of printed data is shown in Fig. 11 on which data, time and average concentration are printed.

$\left[\begin{array}{lllllll}27 & 13 & 0 & 0 & 3 & 4 & 1 \\ 27 & 12 & 0 & 0 & 4 & 8 & 5 \\ 27 & 11 & 0 & 0 & 5 & 1 & 0 \\ 27.10 & 0 & 0 & 3 & 3 & 0 \\ 27 & 9 & 0 & 0 & 2 & 7 & 8 \\ 27 & 9 & 0 & 0 & 2 & 4 & 4 \\ 27 & 7 & 0 & 0 & 2 & 3 & 2 \\ 27 & 6 & 0 & 0 & 1 & 6 & 0 \\ 27 & 5 & 0 & 0 & 1 & 4 & 3 \\ 27 & 6 & 0 & 0 & 1 & 6 & 2\end{array}\right]$

Fig. 11. Prinded data by the automatic dust indicator.

The counting rate of 1 count per hour was adjusted to $0.0033 \mathrm{mg} / \mathrm{m}^{3}$ for the particurate matter in city air. The generation rate of pulse by dark current was 7 c. p. h., and this rate did not change for more than three months.

\section{Discussion}

In this paper, three kinds of apparatus for the measurment of dust concentration in air using the principle of light scattering were presented. Natures of these apparatus are as follows:

1. These apparatus have a high sensitivity and can detect the concentration of the order of $10^{-3} \mathrm{mg} / \mathrm{m}^{3}$ for quartz particle.

2. The measurable range of dust concentration with these apparatus is wide and variable by the change of the capacity of condenser in Fig. 1 or by adjustment of the high power supply for photomultiplier.

Therefore, the apparatus can measure the dust concentration of all range from the concentration corresponding to maximum sensitivity to the highest concentration where a linear relation is held between the dust concentration and the intensity of scattered light.

3. For an identical aerosol system, the counting value for unit time by this apparatus is linearly proportional to the concentration of particulate matter in air as shown in Fig. 12. This nature is the same as the relation between the relative light 


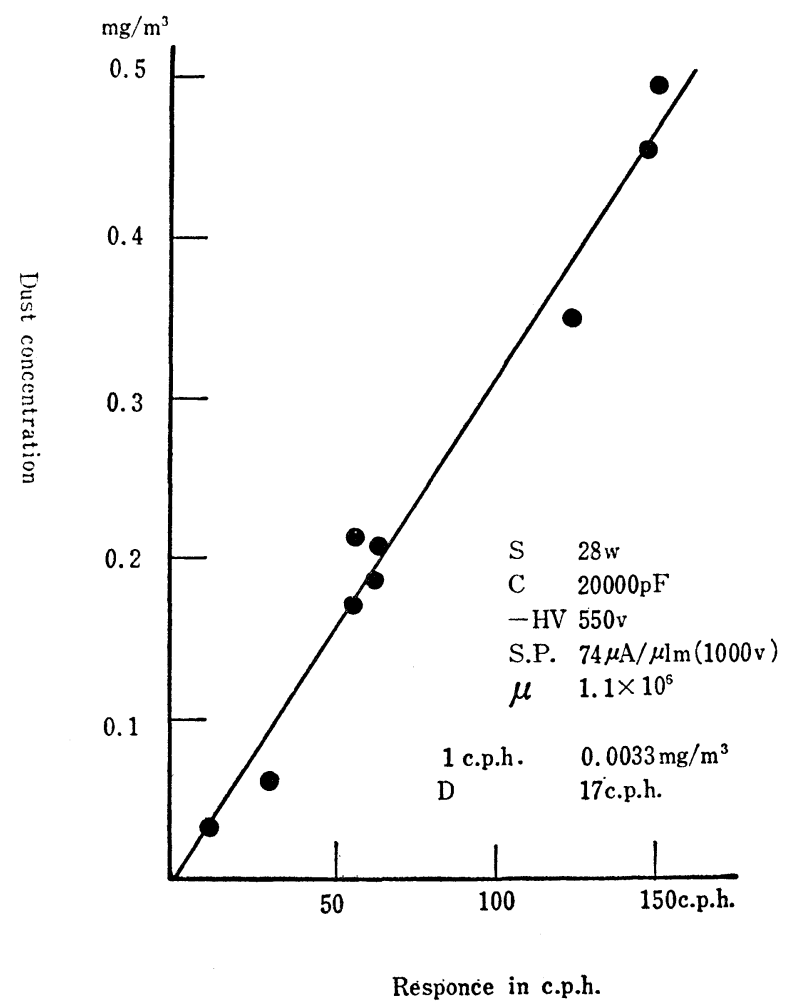

Fig. 12. The relation between dust concentration and response of the automatic aerosol register.

The dust concentration in ordinate have been observed by use of the electrostatic precipitator.

intensity and the dust concentration in Leitz Tyndalloscope.

4. Measurments of dust concentration using relative dust indicator i, e. Tyndalloscope, Filter paper dustometer, Dustallo and Digital dust indicator etc., have a common problem. That is, different responses are obtained for different aerosol systems even if the weight concentrations of particle are the same, because the measured values by these apparatus are independent to the density, size, shape and scattering coefficient of particle. This problem will be discussed in detail in later paper.

5. Calibration of relative dust indicator by analogue measure is very difficult in low concentration because of the fluctuation of air bone dust concentration with time. Whereas, it is easy to calibrate the digital dust indicator if the observation time is extended, for the signal is transformed to digital amount.

The holder with high efficiency filter paper is connected to the outlet of detector and the dust laden air is drawn passing through the detector and filter paper till the weight of dust particles deposited on the filter paper is enough for weighing. The dust concentration corresponding to $1 \mathrm{c}$. p.m. is calculated accurately from the counting rate of the digital dust indicator, the weight of dust particles deposited on the filter 
paper and sampling air volume.

6. In apparatus of measurement of dust concentration by the principle of light scattering, measured values involve the back ground because very small amount of light is produced by the reflection from the inner wall of detector even if the air in the detector is dust free completely.

Since it is difficult to make the dust free air, the accurate measurment of back ground is very difficult under the normal pressure.

Detectors for the apparatus presented in this paper were designed to be able to be vacuous. The back ground is measured in vacuum.

7. Concerning the sampling air velocities, significant differences were not found for a constant dust concentration under suction velocities of air from about $11 / \mathrm{min}$ to $1 \mathrm{~m}^{3} / \mathrm{min}$.

8. Since Digital dust indicator has no device for the collection of particles, there is no need to consider the collecting efficiency of particles.

\section{REFERENCES}

1) Koshi, S. (1958). Bull. Nat. Inst. Ind. Health, 1, 26.

2) Gucker, F. T. and Okonski, C. T. (1949). Chem. Rev., 44, 373.

3) Miura, T. and Kimura, K. (1954). J. Sci. Labour (in Japanese), 30, 722. 